\title{
The design and implementation of a CBT-based intervention for sensory processing difficulties in adolescents on the autism spectrum
}

\author{
Louise Edgington ${ }^{1,2}$, Vivian Hill ${ }^{3}$, \& Elizabeth Pellicano ${ }^{2,4^{*}}$
}

${ }^{1}$ Royal Borough of Kensington and Chelsea, Educational Psychology and Consultation Service, London, UK; ${ }^{2}$ Centre for Research in Autism and Education (CRAE), UCL Institute of Education, University College London, UK; ${ }^{3}$ Department of Psychology and Human Development, UCL Institute of Education, University College London, UK; ${ }^{4}$ School of Psychology, University of Western Australia, Perth, Australia.

Manuscript word count: 5607 words

${ }^{*}$ Corresponding author:

Prof. Liz Pellicano

Centre for Research in Autism and Education (CRAE)

UCL Institute of Education, University College London

55-59 Gordon Square

Tel: $+44(0) 2073315140$

London WC1H 0NU UK Email:I.pellicano@ucl.ac.uk 


\begin{abstract}
Background. Unusual reactions to sensory input now form part of the diagnostic criteria for autism. These features are common and can have an often-devastating impact on autistic individuals and their families. Yet there are few validated interventions that help to remediate or support autistic individuals' adverse sensory experiences. To date, both measurement of sensory experiences and the resulting interventions have been based on assumptions of neurological sensitivities and largely ignored the role of cognition. This study therefore sought to assess the feasibility of a new 8-week CBT-based group intervention for self-regulation of sensory processing difficulties. Method. Seven cognitively able adolescents diagnosed with autism aged 11 to 16 years from one mainstream secondary school received the 8-week intervention. Measures of sensory reactivity, anxiety and repetitive behaviours were taken at baseline, post-intervention and follow-up, 8 weeks after the intervention had ceased. Semi-structured interviews and focus groups were also conducted with adolescents and their parents to examine further the acceptability of the intervention. Results. The results showed that the intervention itself was feasible - both in its implementation and its acceptability to participants. Qualitative analysis clearly showed that the intervention was effective in raising meta-conscious awareness and self-regulation in these autistic adolescents. Analysis of outcome variables showed no significant change over the intervention period, although effect sizes were moderate-to-large. Conclusions. These preliminary results are encouraging and should inform the design of a future pilot randomized controlled trial to test its efficacy with a larger group of participants.
\end{abstract}

Keywords: autism, sensory, intervention, cognitive behavioural therapy, self-regulation

Word count: 243 words 


\section{Highlights}

- Sensory sensitivities are a common yet under-researched feature of autism.

- This study describes the first cognitive-based intervention for sensory processing.

- Results showed that the 8-week group-based intervention was feasible.

- Autistic adolescents reported feeling better able to deal with sensory issues.

- These promising findings warrant testing in a pilot randomised controlled trial. 


\section{Introduction}

Atypical responses to sensory input have long been highlighted as a particular feature of autism (Kanner, 1943). Their recent inclusion in the revised diagnostic criteria for autism (DSM-5; APA, 2013) reflects a growing recognition of their impact and the potentially central role of sensory processing atypicalities to the condition. The behaviours themselves - which range from a fear of hairdryers to a fascination with twinkling lights have been shown to occur in a large proportion of autistic ${ }^{1}$ individuals, across sensory modalities (Ben-Sasson et al., 2009) and across ages (Crane et al., 2009), intellectual abilities and autism severity (Ben-Sasson et al., 2009; Crane et al., 2009; Hochhauser \& Engel-Yeger, 2010). Empirical links between sensory atypicalities and behavioural difficulties (Baker, Lane, Angley, \& Young, 2008; O’Donnell, Deitz, Kartin, Nalty, \& Dawson, 2012), academic achievement (Ashburner, Ziviani, \& Rodger, 2008) and anxiety and depression (Green, Ben-Sasson, Soto, \& Carter, 2012; Mazurek et al., 2012) point to the often-debilitating impact that sensory difficulties can have on individuals' daily lives. Developing interventions to alleviate sensory difficulties for children, adolescents and adults with autism is therefore of considerable importance.

Sensory-based therapies that focus on attempts to reorganise neurological sensory processing by providing sensory input are parents' most commonly requested method to address sensory atypicalities in autism (e.g., Schaaf et al., 2014). This class of therapy includes 'sensory integration therapies' involving a child-specific programme of play activities (e.g., therapy balls and swings) and single sensory strategies such as weighted vests and auditory integration therapy (Baranek, 2002; Case-Smith, Weaver, \& Fristad, 2014). Yet, until very recently, there has been scant evidence for the effectiveness of therapies and still no conclusive evidence for single sensory strategies (Baranek, 2002;

\footnotetext{
1 The term 'autistic person' is the preferred language of many people on the spectrum (see Sinclair, 1999, and Kenny et al., 2015). In this article, we use this term as well as person-first language to respect the wishes of all individuals on the spectrum.
} 
Case-Smith et al., 2014; Dawson \& Watling, 2000). A recent randomised controlled trial (RCT) by Schaaf et al. (2014) showed that sensory integration therapy is effective in producing gains in goals chosen by parents in autistic children aged $4-8$ years, when treatment fidelity was assured. Although promising, this study was nevertheless limited both by the lack of a direct comparison with an equally intensive intervention and the absence of independent blinded measures of outcome (Ashburner, Rodger, Ziviani, \& Hinder, 2014b).

Furthermore, current theoretical accounts suggest that it is not sensory processing itself that is atypical in individuals with autism, but the interpretation of the sensory input (Frith, 2003; Pellicano \& Burr, 2012). Self-report accounts of sensory experiences by autistic individuals support the view that sensory experiences are in fact complex and idiosyncratic, involving past experience and interpretation, cognitions and emotions, suggesting that the observable behaviours ('sensory reactivity') might be only part of the picture. For example, the autistic author Donna Williams (1998) reported 'shutting down' processing in response to an unpleasant 'overload' of sensory information. On the face of it, this could be construed as 'hypo-sensitivity' to sound (i.e., appearing not to hear what you say) but her experience may well be the opposite: a difficulty interpreting and managing auditory information. The prevailing accounts of sensory processing (Ayres, 1972; Dunn 1999) and indeed the measures that capture sensory processing difficulties (e.g., Baranek, David, Poe, Stone \& Watson; Dunn, 1999) may therefore underestimate or misrepresent such difficulties in autism (Ben-Sasson et al., 2009). There is therefore a pressing need for interventions to target individuals' sensory experiences (i.e., at the level of cognition and behaviour), which have hitherto been largely ignored by sensory integration therapies.

Cognitive Behavioural Therapy (CBT), which seeks in part to enhance an individual's self-regulation, provides an alternative framework within which to design an 
intervention for sensory processing difficulties. CBT is focused on the development of selfawareness of the interaction between thoughts, feelings and behaviours in response to environmental triggers (Hofmann, 2011). Guidelines from the United Kingdom's National Institute for Health and Care Excellence (NICE) (2013) already recommend CBT as an approach for the treatment of anxiety in cognitively-able children and young people on the autism spectrum. These guidelines also suggest modifications to standard CBT programmes to accommodate autistic young people's difficulties in, for example, establishing relationships with the therapist, complex language, taking turns in group situations and understanding emotions (Donoghue, Stallard \& Kucia, 2011). In published CBT programmes, these modifications have included emotional education (McConachie et al., 2014; Sofronoff, Attwood \& Hinton, 2005), parental involvement (Chalfant, Rapee \& Carroll, 2007; Reaven, Blakeley- Smith, Culhane- Shelburne \& Hepburn, 2012; Sofronoff, et al., 2005; Wood et al., 2009), visual materials and reward systems (Chalfant, et al. 2007) and the teaching of friendship skills (Wood et al., 2009), relaxation exercises, emotional regulation and cognitive self-control (Sofronoff et al., 2005; Sung et al., 2011). Numerous RCTs have shown that such modified CBT programmes are effective in reducing anxiety in autistic children ranging in age from $8-16$ years, as evidenced by reports in interviews (Chalfant et al., 2007; McConachie et al., 2014; Reaven et al, 2012; Wood et al., 2009, Clarke et al 2016) and on parent and child questionnaires (Chalfant et al., 2007; McConachie et al., 2014; Sofronoff et al., 2005; Sung et al., 2011; Wood et al., 2009).

In view of the suggestion that some anxieties in autism stem from the unpredictable nature of sensory stimuli (Mazurek et al., 2013) and difficulties in sensory interpretation (Hollocks et al., 2013), it is possible that the use of a CBT approach to help manage sensory processing difficulties may also act as a more direct approach to address both anxiety and problematic sensory issues in autistic young people. 
On this basis, we developed an 8-week CBT-based intervention programme to address adolescents' sensory processing difficulties, making the necessary modifications in line with national guidance. The first part of the intervention programme encouraged participants to consider their own sensations, including how they made them act, feel and think, and how these sensations and resulting behaviours might be different from others. In adults, self-report studies with cognitively able autistic participants (Elwin et al., 2013; Jones et al., 2003; Smith \& Sharp, 2012) indicate a conscious awareness of their sensory processing being different, which might help them to develop coping strategies. Strategies identified in these studies were behavioural (e.g., covering ears, avoidance), physical (e.g., being squeezed, rubbing items) and cognitive (e.g., preparing for new situations) in nature, with some unhelpful coping also reported (e.g., retreating "inside my head"; Jones et al., 2003). Yet, to our knowledge, no studies with children (e.g., Ashburner et al., 2013; Kirby et al., 2014) have asked directly about their awareness of their own sensory experiences in relation to others. This intervention programme is therefore the first to examine individuals' conscious awareness of how their sensory experiences relate to others' and impacts upon behaviour.

The second part of the current intervention programme focused on developing strategies in which the children themselves might cope with their own sensory experiences. In self-report studies of sensory experiences in children with autism, coping strategies of avoiding or controlling an unpleasant stimulus are present even in the youngest participants (e.g., Kirby et al., 2014), though these can sometimes result in unhelpful outcomes for the individual (Ashburner et al., 2013; Smith \& Sharp, 2012). As children get older, increasingly sophisticated coping strategies for sensory experiences begin to emerge, including reports of cognitive strategies such as planning and focussing attention (12 to 16 years; Ashburner et al., 2013). These few existing studies suggest that 
adolescents on the autism spectrum have the requisite meta-cognitive skills and motivation to 'self-regulate', in preparation for adulthood.

Here, we assess the feasibility of this 8-week CBT-based intervention programme to support autistic adolescents' conscious awareness and management of their behavioural, emotional, physiological and cognitive responses to sensory stimuli. Feasibility studies are pieces of research conducted before a main study (randomized controlled trial) to answer the question "Can this study be done?" and to inform on its design. Crucially, feasibility studies do not evaluate the outcome of interest; that is left to the main study.

Here, our aims were threefold: to determine (1) whether our CBT-based intervention programme could be implemented successfully, (2) whether it was acceptable to participants and (3) whether the proposed primary and secondary outcome measures were sufficiently sensitive to capture change over the short period between pre- and postintervention. Quantitative (questionnaire-based) and qualitative (interview-based) methods were used to address this aim. Sensory reactivity was identified as the primary outcome, measured on 3 occasions: pre-intervention, post-intervention and follow-up (8 weeks after the intervention ceased). Given that this was an initial feasibility study, secondary outcomes not directly targeted by the intervention were also measured at pre-intervention and follow-up. Repetitive behaviours and anxiety were chosen as secondary outcomes because there is strong evidence of links between these variables and sensory reactivity (Chen, Rodgers \& McConachie, 2009; Gabriels et al., 2008; Mazurek et al., 2013; Pfeiffer, Kinnealey, Reed \& Herzberg, 2005); any gains in regulating sensory processing could therefore influence adolescents' repetitive behaviours and anxiety levels. 


\section{Method}

\section{Participants}

Inclusion criteria for this study were: (1) informed written consent for participation from both parent and adolescent, (2) an independent clinical diagnosis of autism or Asperger's Syndrome, (3) sensory issues, as identified by the school, (4) parent-reported functional hearing and vision, (5) aged between 11 and 16 years in July 2013, (6) sufficient language and literacy to answer written and oral questions, and (7) an IQ of 70 or above (as measured by the Full Scale IQ 2-subtest measure of the Wechsler Abbreviated Scale of Intelligence - II; WASI-II). Our exclusion criterion was the use of psychotropic medications. Participants were not excluded for having a co-occurring diagnosis in addition to autism, due to the high degree of overlap with other conditions, such as ADHD (Simonoff et al., 2008).

Seven male adolescents, aged between 11 and 16 years $(M=13.91$ years; $\mathrm{SD}=1.45$ ), from one mainstream secondary school met these criteria. All participants had received an independent clinical diagnosis of autism $(n=3)$ or Asperger's Syndrome $(n=4)$ according to ICD-10 (WHO, 1993) or DSM-IV-TR (APA, 2000) criteria and most were in receipt of a Statement of SEN, a legal document that details the child's needs and services that the local authority has a duty to provide, which specified autism or Asperger's Syndrome as their primary need. Table 1 shows participants' background information including age, ethnicity, co-occurring diagnoses, intellectual functioning and autism severity, as measured by the Social Responsiveness Scale - Second Edition (SRS-2) (Constantino, 2012). All had functional hearing and vision and were not taking psychotropic medications, as reported by parents. All were also considered "cognitively able", achieving Full-Scale IQ scores in at least the average range, as measured by the Wechsler Abbreviated Scales of Intelligence $-2^{\text {nd }}$ version (WASI-II; Wechsler, 2011) (see Table 1). 


\section{Measures}

Participants completed the primary outcome measures (targeting sensory reactivity) at baseline (0 weeks), post-intervention ( 9 weeks) and follow-up (8 weeks later; 17 weeks). Secondary outcome measures (on repetitive behaviours and anxiety) were completed at baseline and follow-up only.

Primary outcomes measures. Young people were administered the Adolescent/Adult Sensory Profile (AASP) (Brown \& Dunn, 2002), a 60-item self-report questionnaire on sensory preferences and response to experiences. Adolescents rate the frequency of behaviours (e.g., "I only eat familiar foods") on a 5-point scale ranging from 'almost always' (score of 1) to 'never' (score of 5'). The AASP yields 4 subscale scores of avoiding, sensitivity, seeking, and low registration (Dunn, 1999). Total scores were generated in this study by summing scores from the 4 subscales (minimum score $=15$, maximum score $=75$ ). Scores greater than $1 \mathrm{SD}$ above and below the normative means are indicative of greater degrees of sensory atypicality. This scale has been shown to have satisfactory psychometric properties, including good internal consistency (Cronbach's alpha of between .64 to .78 for the total and subscale scores in the standardization sample; Brown \& Dunn, 2002).

Parents completed the Short Sensory Profile (SSP) (Dunn, 1999), a 38-item caregiver-completed version of the Sensory Profile (Dunn, 1999). Like the ASSP, the SSP measures frequency of observable sensory behaviours (e.g., "withdraws from splashing water") on a 5-point scale ranging from 'always' (score of 1) to 'never' (score of 5). A total score was generated by summing seven sensory modality subscale scores yielding a maximum score of 190. Note that the scoring of the SSP is somewhat unusual such that lower scores indicate more atypical sensory behaviours. Mclntosh et al. (1999) demonstrated good psychometric properties for the scale, including adequate internal 
consistency of the total and subscale scores (Cronbach's alpha ranged from 0.68 to 0.92 )

and a discriminant validity of $>95 \%$ in distinguishing children with and without sensory modulation difficulties. As the SSP was used to capture change within the same individuals, raw scores are reported in the current study.

Secondary outcomes measures. The Repetitive Behaviour Questionnaire (RBQ) (Turner, 1999) is a 33-item parent-report questionnaire that measures the frequency of repetitive behaviours (e.g., "Does he/she repeatedly fiddle with toys or other items?) on a 3 or 4-point scale, depending upon the behaviour (e.g., 'never or rarely' (score of 0), '1 bout per day' (score of 1 ), ' 15 bouts daily' (score of 2 ), or '30 bouts daily'= (score of 3$)$ ). The RBQ has good internal consistency (ranging from .80 to .88; Honey et al., 2012). Following Honey, McConachie, Turner, and Rodgers (2012), we calculated two sub-scale scores, one for insistence on sameness/circumscribed interests and one for sensory/motor behaviours, in addition to a total score (maximum score of 76), which also enabled comparison with normative data. Higher scores indicate more repetitive behaviours.

We also administered the Spence Children's Anxiety Scale - Parent (SCAS-P) (Spence, 1997), a 38-item caregiver-report questionnaire that rates the frequency of anxiety-related behaviours (e.g., "my child is scared of the dark") on a 4-point scale ranging from 'never' (score of 0 ) to 'always' (score of 3). This scale has been shown to have good psychometric properties, including excellent internal consistency (Cronbach's alpha of 0.89) (Nauta et al., 2004). Total scores were used in analysis (maximum score $=$ 114), with higher scores indicating greater anxiety. Normative data from Nauta et al. (2004) were used to determine whether total scores were atypical (see Table 1).

Qualitative interviews. Qualitative data from adolescents and parents were collected immediately post-intervention ( 9 weeks) to assess the acceptability of the programme. Adolescents took part in 30-minute focus groups during the week following the completion of the intervention. Semi-structured interviews were also conducted with parents over the 
telephone. During focus groups and interviews, participants were asked open-ended questions regarding the structure, process and outcomes of the intervention, whether the coping tools generated were helpful and the extent to which it met their needs. Interviews were recorded, where possible, for later transcription and analysis.

\section{Procedure}

Ethical approval was granted by the University's Research Ethics Committee. All participants - adolescents and parents - gave their written informed consent to take part in this study. Participant recruitment and procedure is shown in Figure 1.

During the baseline phase (0 weeks), adolescents were seen individually in a quiet room at school on two separate occasions - one 30-minute session to discuss the intervention programme, obtain consent and complete subtests of the WASI-II and AASP and one additional 30-minute session to complete the pre-intervention interviews. Parents completed all questionnaires, including the SRS-2, SSP, RBQ and SCAS-P and returned these via post. At this point, adolescents were divided into two small groups on the basis of their academic year: 'younger' (Years 7-9, $n=3, M$ age=12.61 years, range: $11.58-$ 13.50) and 'older' (Years 10-12, $\mathrm{n}=4, \mathrm{M}$ age=14.97, range: $13.38-15.58)$.

Adolescents were then seen once a week for group-based sessions during school hours for the intervention itself (weeks $1-8$ ). Post-intervention measures (qualitative interview, SSP and AASP) were collected during the week immediately following the 8week intervention period ( 9 weeks). During the follow-up phase, data were collected 8 weeks after the intervention had ceased (17 weeks) to determine whether any changes would be maintained.

Note that adolescents were also receiving a variety of other interventions as part of their education ("services as usual") during the entire period (from baseline to follow-up). 


\section{CBT-based intervention for sensory sensitivities}

The intervention consisted of a pre-intervention individual interview, followed by 8 weekly group sessions, each lasting 45 minutes. The content and rationale for each weekly session, within the overall session structure is shown in Table 2. All interviews, sessions and materials were initially validated for use with typically developing adolescents. The overall intervention structure was based on typical elements of CBT interventions (Hofmann, 2011), while several features and activities within the sessions were adapted from existing CBT programmes for autistic individuals (Attwood, 2004; Chalfant et al., 2007; McConachie et al., 2014; Reaven et al., 2012; Sofronoff, et al. 2005; Sung et al., 2011; Wood et al., 2009) and the self-reports of autistic sensory coping strategies (Ashburner et al., 2013; Jones et al., 2003; Smith \& Sharp, 2012).

The pre-intervention interview addressed the CBT stages of establishing rapport, problem discussion, and identifying the adolescents' goals for change, but also started the process of bringing some sensory experiences and coping strategies to consciousness. The first 4 intervention sessions addressed the next CBT stage of 'problem formulation' by building adolescents' awareness of their own thoughts, feelings and behavioural responses to sensory situations. Participants' recall of sensory experiences and engagement in the activities were facilitated by interaction with 'live' sensory stimuli from a 'feely box' (containing, for example, a hairdryer, chocolate), drawing on Robertson's (2012) approach. Half of the items in the feely box were included in response to participants' sensory preferences expressed during the pre-intervention interviews, thereby personalising some experiences, as in Kirby et al. (2014). In all sessions, participants drew 'sensory pictures': templates of a 'stick-man' representation illustrating the interplay between thoughts, feelings (body and emotional) and behaviours and outcomes. The final 4 sessions focused on identifying and experimenting with new behaviours (e.g., role play asking someone to stop doing), feelings (e.g., breathing relaxation exercises, listening to 
music) and thoughts (e.g., I'm safe, just keep focus on what I'm doing), referred to as 'coping tools'. Coping tools were chosen to reflect the type and order in which they emerge through development in self-reports of coping strategies in autism (Ashburner et al., 2013; Jones et al., 2003; Smith \& Sharp, 2012).

When considering sensory experiences throughout each session, participants were encouraged to work with their own examples. If adolescents had difficulty selecting a sensory experience for consideration, they were prompted with an example from a personalised list of likes and dislikes, collated from their responses during their preintervention interviews and questionnaires. Adolescents were provided with a 'prompt' sheet of examples of emotions (Henry, 2013) and body feelings to build up their emotional vocabulary, following Attwood (2004).

Sessions were timetabled to fit with the school's curriculum and delivered in a familiar room in school. Steps were taken to establish rapport with pupils prior to the intervention. The structure of each session in the current intervention was consistent for all 8 sessions and consisted of 6 parts: (1) 'checking-in' (sharing recent progress and events), (2) providing an overview of the session outline, (3) an introduction and demonstration of ideas, (4) an opportunity for the participants to 'have a go', (5) a plenary where the ideas were shared and (6) a homework task set. The homework task (termed a 'mission') was optional for students to complete and a sticker-based visual reward system (linked to the school's reward system) was used to motivate engagement, following Chalfant et al. (2007). Parents were emailed weekly copies of the resources and were encouraged to ask questions or communicate any events, experiences or thoughts. Time for sharing sensory pictures was built in at the beginning and end of sessions, so that adolescents developed a sense of how others may perceive and respond to stimuli differently. This was an important aspect of the intervention, as individuals' awareness of how their sensory 
experiences might be different to others' has been implicated in the development of conscious coping strategies (Smith \& Sharp, 2012).

We measured fidelity to the intervention (i.e., the extent to which the researcher carried out the intervention as specified) using a check-list approach, assessing the presence or absence of core components (the 6 parts) on a session-by-session basis. The researcher also received ongoing clinical supervision and training throughout the study.

\section{Data Analysis}

To address our first and second aims regarding implementation and acceptability of the intervention, we analysed qualitative data from interviews and notes taken during data collection. All recordings from pre- and post-intervention interviews were transcribed verbatim, checked for accuracy and re-read several times to ensure familiarity with the data. Inductive thematic analyses were conducted on the post-intervention focus groups with adolescents and post-intervention interviews with parents, using Nvivo10. Analysis was carried out systematically by all authors, following the steps described in Braun and Clarke (2006), guided by the aim of understanding and supporting sensory experiences.

To address our third aim, pre- and post-intervention questionnaire data were analysed to assess any change in the primary outcome (sensory reactivity) and secondary outcome (repetitive behaviours and anxiety) measures. Preliminary data analyses suggested participants' data met the assumptions of normality except for several subscales of the SSP; therefore, only total SSP scores were used in subsequent analyses. Repeated measures ANCOVA were performed for each of the dependent variables ${ }^{2}$ (SSP, AASP, RBQ, SCAS-P). For each analysis, measures of age, intellectual functioning (WASI-2) and autism severity (SRS-2) scores were entered as covariates.

\footnotetext{
2 Individual level analyses were also carried out using the Reliable Change Index (Hsu, 1999) to consider whether individual changes in each outcome variable were significant and not attributable to measurement error. This analysis, however, showed no significant results so is not reported here.
} 


\section{Results}

\section{Qualitative analysis}

All 7 adolescents completed the intervention. The total attendance rate was $92.8 \%$, with only 4 individual pupils absent during any session over the 8-week intervention period (due to overall school absence). The researcher achieved extremely high fidelity (100\%) and adolescents' engagement in the activities was high, with all adolescents contributing ideas and drawing sensory pictures when asked. Each adolescent completed between 10-25 sensory pictures in total. Group sizes of 3-4 students were appropriate, being small enough to allow each to participate and receive individual attention from the group leader. 'Mission' completion rates were not recorded since these were optional; nevertheless, approximately half of participants completed the Mission following any one session. All took part in the post-intervention focus groups (adolescents) and interviews (parents).

Adolescents' perceptions of the intervention. Overall, participants were positive about the intervention itself and also reported that it had an impact on their own cognitions and behaviour. Analysis of focus group discussions identified 5 themes. Adolescents showed raised awareness of sensory experiences, referring to the need to consider 'outcomes', the relation between thoughts, feelings and behaviours (e.g., "I've learnt that my thoughts are ... what do you call it? ... have an impact on my body and when I'm angry I get tense and my emotions go everywhere"). They also showed an awareness of how their experiences relate to others: "I also learnt that anyone has sensory problems, not really just people with, like, autism ... and autism might be to do with it, but it might not."

Adolescents also reported a new-found self-expression, facilitated by new vocabulary acquisition, supportive group dynamics (e.g., "It was fun. We got together, we went through sensory experiences and we sort of helped each other") and the opportunity 
for expression (e.g., “I don't normally tell people about how I'm feeling usually but I think I'm actually encouraged to tell people about it and then that's, like, a good thing").

The boys also reported motivation for using coping strategies. They described several situations in which they used coping tools they learned during the intervention, including relieving stress, self-restraint, avoiding conflict and self-motivation (e.g., "well, the one I'm most proud of is the one where the guy's pestering me and I counted to relieve pressure on me"; "like when people are telling me that I have to behave myself more I didn't really know how to but now I found a way how to"; "probably the breathing one ... I won't flip out on someone now"). There was also evidence that this learning generalized such that some adolescents had confidence in their ability to apply coping tools to new situations or to learn a new coping tool (e.g., "I could learn a coping tool that I talk to people I know and I just talk and not play rough"). In terms of improvements to the programme, these largely consisted of requests for a greater number of sessions.

Parents' perceptions of the intervention. Thematic analysis of parents' responses during post-intervention interviews identified 5 themes. Parents reported several challenges to parental involvement, including in particular the difficulty in obtaining any direct information from adolescents, who were generally evasive and resistant to their involvement (e.g., "Basically he wasn't interested in telling us much about it, other than he was enjoying it and he liked being in the groups"). As a result, the parents stressed the importance of communication with parents. They were positive about the way in which the facilitator communicated knowledge about the intervention on a weekly basis, which aided their communication and understanding. One mother said: "I liked very much the fact that [facilitator] was sending us every week the update. That was really nice in terms of being able to talk with [child] about what he was doing."

Parents also reported several post-intervention changes in their children, including the use of new coping tools and a growth in maturity. One mother said: "He has been 
sitting down and doing these amazing drawings, very intricate. He gets quite a lot of satisfaction from it cause it's quite a visual thing for him to do and very calming so I was wondering if maybe, that was mentioned in the course, about doing things, drawing something when you feel tense. On that occasion that really worked." Another mother reported that her child "seems calmer again. He was going through a stage of being quite unsettled and almost fighting with his conscience all the time. Since he's being doing the groups he seems to kind of got out of that and to have grown up, almost, if that makes sense."

Like the adolescents, parents also identified the importance of group dynamics, which included feeling comfortable with the adult leader, having a "safe space to think" and being able to both identify with peers and see how far their experiences differ (e.g., "It was giving him this buddy situation. The sort of situation where he was understood, not judged"; "I think it's been good for him to think about how he finds some things more difficult than other people").

In terms of improvements in future support and delivery, several parents suggested the possibility of embedding learning into daily routines and making more support available at times of increased stress.

\section{Quantitative analysis}

All 7 adolescents completed the AASP at pre-intervention, post-intervention and follow-up. The outcome measures of SCAS-P and RBQ were completed by all parents at pre-intervention and follow-up. The SSP was completed by all 7 parents at all three timepoints, with the exception of one parent who did not complete the SSP post intervention.

Table 3 summarises the results from the comparison of outcome measures taken at each time-point. Overall, analyses indicated no significant changes in scores over the three time points on the primary outcome variables (the SSP and AASP), nor between pre- 
intervention and follow-up for the secondary outcome variables (the SCAS-P and RBQ). Repeated-measures ANCOVA analyses, with age, SRS and WASI-II scores as covariates revealed no significant change for the total AASP score, $F(1.14,3.42)=2.46, p=.21$, $\eta_{p}{ }^{2}=.46$, or any of the subscale scores (AASP low registration: $F(1.03,3.07)=2.41, p=.22$, $\eta_{p}^{2}=.45 ;$ AASP sensation seeking: $F(1.51,4.52)=4.64, p=.09, \eta_{p}^{2}=.61 ;$ AASP sensory sensitivity: $F(1.65,4.96)=3.07, p=.14, \eta^{2}=.51$; AASP sensation avoiding: $F(1.08$, $3.23)=1.67, p=.29, \eta_{p}^{2}=.36$ (Greenhouse-Geisser corrected). Similarly, for the parentreport measures (the SSP), a repeated-measures ANCOVA showed no significant effect of the intervention on SSP total scores over the three time points, $F(1.73,3.47)=1.93, p=.27$, $\eta_{\mathrm{p}}^{2}=.49$. It is noteworthy that although the overall effects are not significant, changes were in the expected direction and the effect sizes (as estimated by partial eta squared) are moderate-to-large.

Analyses on scores for the secondary outcome measures revealed no significant effects of time for the RBQ total score, $F(1,3)=.003, p=.96, \eta_{p}^{2}=.00$, or subscale scores (RBQ insistence on sameness: $F(1,3)=.84, p=.43, \eta_{p}^{2}=.23$; RBQ sensory motor: $F(1$, $\left.3)=.68, p=.47, \eta_{p}{ }^{2}=.19\right)$ or the SCAS-P, $F(1,3)=.40, p=.57, \eta_{p}^{2}=.12$. Surprisingly, changes to the SCAS-P and RBQ group means were in the unexpected direction, suggesting an increase in parent-reported anxiety and repetitive behaviours in adolescents.

\section{Discussion}

Atypicalities in sensory processing can have a significant impact on autistic individuals' everyday quality of life, as suggested by links with behavioural difficulties (Baker et al., 2008; O'Donnell et al., 2012), academic achievement (Ashburner et al., 2008) and anxiety and depression (Green et al., 2012; Mazurek et al., 2013). This study assessed the feasibility of a new 8-week CBT-based intervention to manage sensory processing difficulties. The intervention is the first sensory self-regulatory intervention programme for 
adolescents on the autism spectrum, embracing both current theories of autistic perception (Frith, 2003; Pellicano \& Burr, 2012) and the autistic experience (Ashburner et al., 2014a), through its focus on bringing the cognitions, emotions, and responses involved in sensory experiences to awareness.

The results of this feasibility study provide clear evidence of the acceptability of the intervention - for both adolescents and their parents. The aims of the intervention were to bring sensory experiences to awareness, by developing adolescents' understanding and expressive language in relation to sensory experiences, and to equip adolescents with an understanding of how their experiences may be different or similar to others', thus enabling them to cope with specific, problematic situations. The interview and focus group data suggest that the intervention was successful in this regard. Both adolescents and parents reported positive changes as a result of the intervention. First, adolescents reported a new awareness of the relationship between their thoughts, feelings, behaviours and outcomes and how their experience compares to others. They also learned to self-regulate and modify their behaviours to avoid conflict or ameliorate an unpleasant experience, with some adolescents generalising their learning, applying the 'coping tool' strategy in new contexts or to broader situations such as homework. At home, several parents noticed some new observable 'coping' behaviours in adolescents and also a newfound sense of maturity. Second, the supportive group atmosphere of the intervention was also identified as a therapeutic element in itself. Finally, equipping parents with knowledge from the groups facilitated their communication and understanding and in some cases allowed them to engage more with their child about their challenges.

Overall, the intervention was positively evaluated by participants, whose only suggested improvements were to increase the number of sessions and to embed them into adolescents' daily lives. The high attendance rates and participant engagement within sessions also demonstrates it can be implemented successfully within the complexities of 
a mainstream secondary school. This finding of good acceptability to participants is consistent with that of other CBT-based interventions with children and adolescents with autism (e.g., Clarke et al., 2016; McConachie et al., 2014), providing further evidence for the suitability of this approach with young autistic people.

We also examined the characteristics of our outcome variables in order to determine whether they were sufficiently sensitive to capture change over a relatively brief period. We found no evidence of significant change in the primary outcome (sensory reactivity) or secondary outcomes (repetitive behaviours and anxiety) over the short period of the intervention. This is perhaps not surprising given the small sample size and the variability in participants' baseline scores, as might be expected from a heterogeneous autistic population (Happé \& Ronald, 2008). Notwithstanding, the magnitude of the effect sizes for the measures of sensory reactivity was moderate-to-large suggesting that significant gains might be borne out in a larger sample of individuals.

These apparent reductions in sensory reactivity were also accompanied by unexpected (albeit non-significant) increases in our secondary outcome variables, parentreported anxiety and repetitive behaviours, over the course of the intervention. While these changes could well be due to be measurement error and variability due to the small sample size, they might also reflect parents' increased awareness of these behaviours in their children. In other words, the weekly communication with parents may have caused them to re-evaluate or pay more attention to certain anxiety-related and repetitive behaviours, leading them to endorse more behaviours on the follow-up questionnaire. Alternatively, it is also possible that the rise in adolescents' anxiety and repetitive behaviours was in fact real. The intervention aimed to bring possible differences to awareness, which may well have generated some anxiety as young people reflected on and re-evaluated their experiences. Future studies should seek to use more objective, physiological measures of anxiety such as heart rate or skin conductance measures, and 
observation measures of repetitive behaviours to monitor these behaviours more closely and reliably.

Additional factors, such as the inclusion of participants with varying baseline sensory scores (these were not selected a priori) and the reasonably short 8-week timescale between data collection points, may have made it difficult to detect any effects on adolescents' sensory reactivity. Moreover, as the questionnaires measure observable behaviours that are of potential concern to parents (e.g. fussy with foods; Dunn, 1999), they may have limited power to detect the changes in the scenarios that were chosen by adolescents themselves, namely in the areas of behavioural and stress self-regulation and avoiding conflict associated with sensory experiences.

Despite these limitations, this work is the first to our knowledge to design and empirically evaluate the feasibility - its implementation, acceptability and limited preliminary efficacy - of a CBT group-based intervention programme for young autistic people's sensory processing difficulties. The data reported herein should be used to inform the design of a future pilot randomized controlled trial to test the programme's efficacy, with careful consideration of primary and secondary outcome measures. Traditional measures of sensory reactivity were unable to capture change adequately in this sample. Caution is therefore warranted over the use of these measures in the evaluation of an intervention that adopts a child-centred approach and allows adolescents to choose their own issues upon which to focus. Changes were instead clearly captured in parents and adolescents' reports, indicating striking gains in meta-awareness, expression and use of language, sense of self in-relation-to others, use of new coping behaviours and for some, an increased sense of maturity. These findings suggest that this programme could be a promising intervention for professionals to implement in schools to relieve sensory sensitivities and support the management of sensory difficulties. Particular attention will need to be paid to participants' anxiety, which may increase as a result of the intervention. 


\section{Conclusion}

As indicated by parents in the current study, autistic adolescents rarely communicate their sensory experiences, meaning that they may often go unrecognised. The focus of the current school-based programme fits squarely with the aims of other UK initiatives to increase access to mental health support in schools. For example, Mental Health and Behaviour in Schools (Department for Education, 2014) intends to "help schools promote mental health in their pupils and identify and address those less severe problems at an earlier stage and build their resilience" (p. 4). The strong qualitative evidence reported herein supports the feasibility of this CBT-based sensory intervention as a potential psycho-educational therapeutic intervention in schools for young people on the autism spectrum. The next step is to test the intervention's efficacy using a pilot randomized controlled trial with larger samples of adolescents. 


\section{Acknowledgements}

We are very grateful to the young people and their parents for taking part in this project and to the school staff who made this possible. EP was supported by a grant from the UK's Medical Research Council (MR/J013145/1) for the period of this work. Research at

the Centre for Research in Autism and Education (CRAE) is also generously supported by The Clothworkers' Foundation and Pears Foundation.

\section{Conflicts of Interest}

We have no conflicts of interest of which we are aware. 


\section{References}

American Psychiatric Association. (2000). Diagnostic and statistical manual of mental disorders (4th ed., text rev.). Washington, DC: APA.

American Psychiatric Association. (2013). Diagnostic and Statistical Manual of Mental Disorders (5th Ed.) (DSM-5). Washington DC: American Psychiatric Association.

Ashburner, J., Bennett, L., Rodger, S., \& Ziviani, J. (2013). Understanding the sensory experiences of young people with autism spectrum disorder: A preliminary investigation. Australian Occupational Therapy Journal, 60, 17180.

Ashburner, J., Ziviani, J., \& Rodger, S. (2008). Sensory processing and classroom emotional, behavioral, and educational outcomes in children with autism spectrum disorder. The American Journal of Occupational Therapy, 62, 564573.

Ashburner, J. K., Rodger, S. A., Ziviani, J. M., \& Hinder, E. A. (2014a). Optimizing participation of children with autism spectrum disorder experiencing sensory challenges: A clinical reasoning framework. Canadian Journal of Occupational Therapy, 81, 29-38.

Ashburner, J. K., Rodger, S. A., Ziviani, J. M., \& Hinder, E. A. (2014b). Comment on: "An intervention for sensory difficulties in children with autism: A randomiszed trial" by Schaaf et al. (2013). Journal of Autism and Developmental Disorders, 44, 1486-8.

Attwood, T. (2004). Exploring feelings: Cognitive behaviour therapy to manage anxiety. Arlington, Texas: Future Horizons.

Ayres, A. J. (1972). Sensory integration and learning disabilities. Los Angeles: Western Psychological Services. 
Baker, A. E. Z., Lane, A., Angley, M. T., \& Young, R. L. (2008). The relationship between sensory processing patterns and behavioural responsiveness in autistic disorder: A pilot study. Journal of Autism and Developmental Disorders, 38, 867-875.

Baranek, G. T. (2002). Efficacy of sensory and motor interventions for children with autism. Journal of Autism and Developmental Disorders, 32, 397-422.

Baranek, G. T., David, F. J., Poe, M. D., Stone, W. L., \& Watson, L. R. (2005). Sensory Experiences Questionnaire: Discriminating sensory features in young children with autism, developmental delays, and typical development. Journal of Child Psychology and Psychiatry, 47, 591-601.

Barrett, P. (2004). FRIENDS for life: Group leader's manual for children. Brisbane, Australia: Australian Academic Press.

Ben-Sasson, A., Hen, L., Fluss, R., Cermak, S. A., Engel-Yeger, B., \& Gal, E. (2009). A meta-analysis of sensory modulation symptoms in individuals with autism spectrum disorders. Journal of Autism and Developmental Disorders, $39,1-11$.

Braun, V., \& Clarke, V. (2006). Using thematic analysis in psychology. Qualitative Research in Psychology, 3, 77-101.

Brown, C., \& Dunn, W. (2002). Adolescent/Adult Sensory Profile: User's manual. San Antonio, TX: Psychological Corporation.

Case-Smith, J., Weaver, L. L., \& Fristad, M. A. (2014). A systematic review of sensory processing interventions for children with autism spectrum disorders. Autism, 1362361313517762 [epublication ahead of print].

Chalfant, A. M., Rapee, R., \& Carroll, L. (2007). 'Treating anxiety disorders in children with high functioning autism spectrum disorders: A controlled trial'. Journal of Autism and Developmental Disorders, 37 (10), 1842-1857. 
Chen, Y., Rodgers, J., \& McConachie, H. (2009). Restricted and repetitive behaviours, sensory processing and cognitive style in children with autism spectrum disorders. Journal of Autism and Developmental Disorders, 39, 635-642.

Clarke, C., Hill, V., \& Charman, T. (2016). School based cognitive behavioural therapy targeting anxiety in children with autistic spectrum disorder: a quasiexperimental randomised controlled trial incorporating a mixed methods approach. Journal of Autism and Developmental Disorders. Published online April 2016.

Constantino, J. (2012). Social Responsiveness Scale, Second Edition (SRS-2). Los Angeles: Western Psychological Services.

Crane, L., Goddard, L., \& Pring, L. (2009). Sensory processing in adults with autism spectrum disorders. Autism, 13, 215-228.

Dawson, G., \& Watling, R. (2000). Interventions to facilitate auditory, visual, and motor integration in autism: A review of the evidence. Journal of Autism and Developmental Disorders, 30, 415-421.

Department for Children, Schools and Families. (2008). Targeted Mental Health in Schools Project (TAMHs). Nottingham: DCSF publications.

Department for Education. (2014). Draft Special Educational Needs (SEN) Code of Practice: for 0 to 25 years. London.

Department for Education. (2014). Mental Health and Behaviour in Schools. London.

Donoghue, K., Stallard, P., \& Kucia, J. (2011). The clinical practice of Cognitive Behavioural Therapy for children and young people with a diagnosis of Asperger's Syndrome. Clinical Child Psychology and Psychiatry, 16, 89-102. Dunn, W. (1999). Sensory Profile. San Antonio, TX: Psychological Corporation 
Elwin, M., Ek, L., Kjellin, L., \& Schroder, A. (2013). Too much or too little: Hyperand hypo-reactivity in high-functioning autism spectrum conditions. Journal of Intellectual and Developmental Disability, 38, 232-241.

Frith, U. (2003). Autism: Explaining the enigma. London: Wiley-Blackwell.

Gabriels, R. L., Agnew, J. A., Miller, L. J., Gralla, J., Pan, Z., Goldson, E., Ledbetter, J. C., Dinkins, J. P., \& Hooks, E. (2008). Is there a relationship between restricted, repetitive, stereotyped behaviors and interests and abnormal sensory response in children with autism spectrum disorders?. Research in Autism Spectrum Disorders, 2, 660-670.

Gaudion, K., \& Edgington, L. (2012). Sensory School Cards. Unpublished project, Royal College of Art London.

Green, S. A., Ben-Sasson, A., Soto, T. W., \& Carter, A. S. (2012). Anxiety and sensory over-responsivity in toddlers with autism spectrum disorders: Bidirectional effects across time. Journal of Autism and Developmental Disorders, 42, 1112-1119.

Happé, F., \& Ronald, A. (2008). The 'fractionable autism triad': A review of evidence from behavioural, genetic, cognitive and neural research. Neuropsychology Review, 18 (4), 287-304.

Henry, M. (2013). Emotions/Sentiments. [Online]. Available at: http://www.henry4school.fr/Vocabulary/emotion.htm. [Last accessed 1.7.13].

Hochhauser, M., \& Engel-Yeger, B. (2010). Sensory processing abilities and their relation to participation in leisure activities among children with highfunctioning autism spectrum disorder (HFASD). Research in Autism Spectrum Disorders, 4, 746-754.

Hofmann, S. G. (2011). An introduction to modern CBT: Psychological solutions to mental health problems. London: Wiley. 
Hollocks, M. J., Ozsivadjian, A., Matthews, C. E., Howlin, P., \& Simonoff, E. (2013). 'The relationship between attentional bias andanxiety in children and adolescents with autism spectrum disorders'. Autism Research, 6 (4), 237247.

Honey, E., McConachie, H., Turner, M., \& Rodgers, J. (2012). 'Validation of the Repetitive Behaviour Questionnaire for use with children with autism spectrum disorder'. Research in Autism Spectrum Disorders, 6 (1), 355-364.

Hsu, L. (1999). A comparision of three methods of identifying reliable and clinically significant changes: Commentary on Hageman and Arrindell. Behaviour Research and Therapy, 37, 1195-1202.

Jones, R., Quigney, C., \& Huws, J. (2003). First-hand accounts of sensory perceptual experiences in autism: A qualitative analysis. Journal of Intellectual and Developmental Disability, 28, 112-121.

Kanner, L. (1943). Autistic disturbances of affective contact. Nervous Child, 2, 21750.

Kenny, L., Hattersley, C., Molins, B., Buckley, C., Povey, C., \& Pellicano, E. (2015). What terms should we use to describe autism? Perspectives from the UK autism community. Autism, in press.

Kirby, A. V., Dickie, V. A., \& Baranek, G. T. (2014). Sensory experiences of children with autism spectrum disorder: In their own words. Autism,1362361314520756 [epublication ahead of print].

Mazurek, M., Vasa, R., Kalb, L., Kanne, S., Rosenberg, D., Keefer, A., Murray, D., Freedman, B., \& Lowery, L. (2013). Anxiety, sensory over-responsivity, and gastrointestinal problems in children with autism spectrum disorders. Journal of Abnormal Child Psychology,41, 165-176. 
McConachie, H., McLaughlin, E., Grahame, V., Taylor, H., Honey, E., Tavernor, L., Rodgers, J., Freeston, M., Hemm, C., Steen, N., \& Le Couter, A., (2014). Group therapy for anxiety in children with autism spectrum disorder. Autism, $18,723-732$.

Nauta, M. H., Scholing, A., Rapee, R. M., Abbott, M., Spence, S. H., \& Waters, A. (2004). 'A parent-report measure of children's anxiety: Psychometric properties and comparison with child-report in a clinic and normal sample'. Behaviour Research and Therapy, 42 (7), 813-839.

NICE (2013). Autism: The management and support of children and young people on the autism spectrum. [Online]. Available at: http://www.nice.org.uk/CG170, [Last accessed 19.1.15].

O’Donnell, S., Deitz, J., Kartin, D., Nalty, T., \& Dawson, G. (2012). Sensory processing, problem behavior, adaptive behavior, and cognition in preschool children with autism spectrum disorders. The American Journal of Occupational Therapy, 66, 586-594.

Pellicano, E., \& Burr, D. (2012). When the world becomes 'too real': a Bayesian explanation of autistic perception. Trends in Cognitive Sciences, 16, 504510.

Pfeiffer, B., Kinnealey, M., Reed, C., \& Herzberg, G. (2005). Sensory modulation and affective disorders in children and adolescents with Asperger's disorder. The American Journal of Occupational Therapy, 59, 335-345.

Reaven, J., Blakeley- Smith, A., Culhane- Shelburne, K., \& Hepburn, S. (2012). Group cognitive behavior therapy for children with high- functioning autism spectrum disorders and anxiety: A randomized trial. Journal of Child Psychology and Psychiatry, 53, 410-419. 
Robertson, A. (2012). Sensory experiences of individuals with autism spectrum disorder and autistic traits: A mixed methods approach. Unpublished Thesis, Glasgow University, Glasgow.

Schaaf, R. C., Benevides, T., Mailloux, Z., Faller, P., Hunt, J., van Hooydonk, E., et al. (2014). An intervention for sensory difficulties in children with autism: A randomized trial. Journal of Autism and Developmental Disorders, 44, 1493506.

Simonoff, E., Pickles, A., Charman, T., Chandler, S., Loucas, T., \& Baird, G. (2008). Psychiatric disorders in children with autism spectrum disorders: Prevalence, comorbidity, and associated factors in a population-derived sample. Journal of the American Academy of Child and Adolescent Psychiatry, 47, 921-929.

Smith, R., \& Sharp, J. (2012). Fascination and isolation: A grounded theory exploration of unusual sensory experiences in adults with asperger syndrome. Journal of Autism and Developmental Disorders, 43, 891-910.

Sofronoff, K., Attwood, T., \& Hinton, S. (2005). 'A randomised controlled trial of a CBT intervention for anxiety in children with Asperger syndrome'. Journal of Child Psychology and Psychiatry, 46 (11), 1152-1160.

Spence, S. H. (1997). Structure of anxiety symptoms among children: A confirmatory factor-analytic study. Journal of Abnormal Psychology, 106, 280-297.

Sung, M., Ooi, Y. P., Goh, T. J., Pathy, P., Fung, D. S., Ang, R. P., \& Lam, C. M. (2011). Effects of cognitive-behavioral therapy on anxiety in children with autism spectrum disorders: a randomized controlled trial. Child Psychiatry \& Human Development, 42, 634-649.

Therapro Inc. (2011). Sensory Stories. [Online]. Available at: http://www.sensorystories.com/. [Last accessed 28.3.14]. 
Turner, M. (1999). Annotation: Repetitive behaviour in autism: A review of psychological research. The Journal of Child Psychology and Psychiatry and Allied Disciplines, 40, 839-849.

Wechsler, D. (2011). Wechsler Abbreviated Scale of Intelligence - Second Edition (WASI-II). San Antonio, TX: PsychCorp.

Williams, D. (1998). Autism and sensing: The unlost instinct: London: Jessica Kingsley.

Williams, M. S., \& Shellenberger, S. (1994). How does your engine run?: Leader's guide to the alert programme for self-regulation. TherapyWorks, Inc.

Wood, J. J., Drahota, A., Sze, K., Har, K., Chiu, A., \& Langer, D. A. (2009). Cognitive behavioral therapy for anxiety in children with autism spectrum disorders: A randomized, controlled trial. Journal of Child Psychology and Psychiatry, 50, 224-234.

World Health Organisation (1992). ICD-10 Classifications of Mental and Behavioural Disorder: Clinical Descriptions and Diagnostic Guidelines. Geneva: World Health Organisation. 
Figure Caption

Figure 1. Participant recruitment and procedure. 
Table 1. Individual participant demographics.

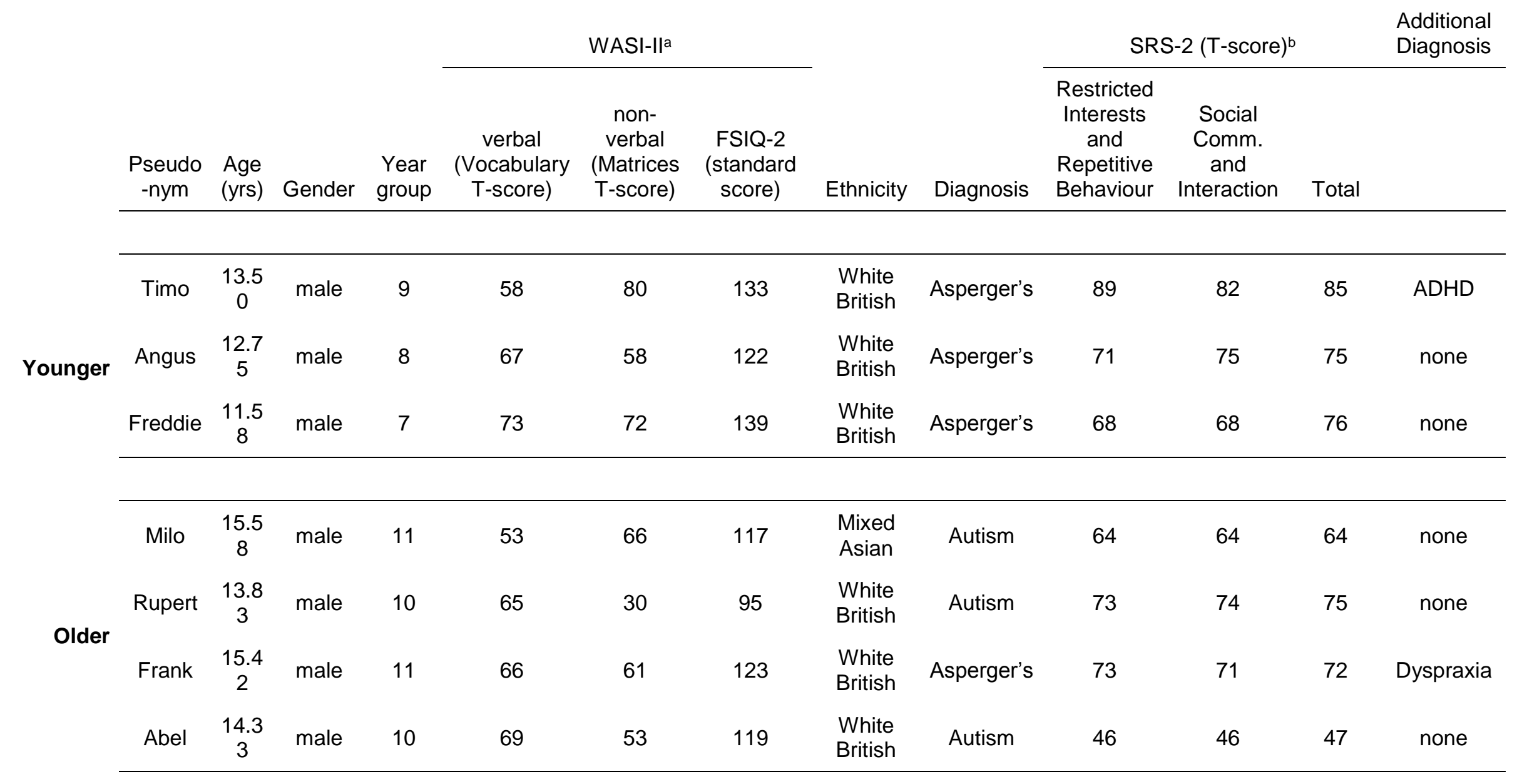

Notes: aWASI-II: Wechsler Abbreviated Scale of Intelligence - Second Edition (Wechsler, 2011); bSRS2: Social Responsiveness Scale - Second Edition; higher scores indicate greater autism severity. Other abbreviations: FSIQ-2: Full Scale IQ 2-subtest composite; ADHD: attention deficit/hyperactivity disorder 
Table 2. The 8-week Cognitive Behavioural Therapy based intervention for sensory processing difficulties: Session outlines and rationale.

\begin{tabular}{|c|c|c|}
\hline & Main Activities within overall structure & Purpose /Rationale \\
\hline $\begin{array}{l}\text { Pre- } \\
\text { intervention } \\
\text { interviews }\end{array}$ & $\begin{array}{l}\text { - Participants complete 'card sort' of likes } \\
\text { and dislikes for different sensory stimuli } \\
\text { - For } 2 \text { likes and } 2 \text { dislikes, participants } \\
\text { are asked semi-structured interview } \\
\text { questions around their responses to } \\
\text { stimuli, awareness of others' responses } \\
\text { and existing coping strategies }\end{array}$ & $\begin{array}{l}\text { - Addressed the CBT stages of } \\
\text { establishing rapport, problem discussion, } \\
\text { and identifying goals for change, but also } \\
\text { started the process of bringing some } \\
\text { sensory experiences and coping to } \\
\text { consciousness } \\
\text { - The 'School Sensory Cards' depicting } \\
\text { images of sensory stimuli (e.g. flicking } \\
\text { pages) (Gaudion \& Edgington, 2012, } \\
\text { used in Edgington, 2012) used to } \\
\text { stimulate discussion }\end{array}$ \\
\hline $\begin{array}{l}\text { Session 1: } \\
\text { Introduction }\end{array}$ & $\begin{array}{l}\text { - Share ideas around the meaning of the } \\
\text { term 'sensory' and agree group 'rules', } \\
\text { writing on one large piece of paper. } \\
\text { - Structured dynamic 'ice-breaker' game: } \\
\text { what's your favourite... (e.g. computer } \\
\text { game) } \\
\text { - Use prompt sheets to describe emotional } \\
\text { and body responses to 'favourite' things }\end{array}$ & $\begin{array}{l}\text { - } \quad \begin{array}{l}\text { Foster a sense of collaborative group } \\
\text { work and positive group dynamics }\end{array} \\
\text { - Introduce idea of individual differences/ } \\
\text { self in-relation-to others (Smith \& Sharp, } \\
\text { 2012) } \\
\text { - Emotional language education (Attwood) }\end{array}$ \\
\hline $\begin{array}{l}\text { Session 2: } \\
\text { Introduction } \\
\text { to CBT } \\
\text { model: } \\
\text { Positive } \\
\text { experiences }\end{array}$ & $\begin{array}{l}\text { - Demo Sensory picture completed by } \\
\text { leader (e.g. roller coaster, having a bath) } \\
\text { - Participants consider thoughts, body and } \\
\text { emotion feelings and behaviours while } \\
\text { eating chocolate } \\
\text { - Complete sensory picture for chocolate } \\
\text { experience, then for own choice of } \\
\text { pleasant sensory experiences }\end{array}$ & $\begin{array}{l}\text { - Demonstrate interplay between thoughts, } \\
\text { feelings and behaviour - } \\
\text { 'psychoeducation' (Hoffman, 2011) } \\
\text { - Encourages attention on current sensory } \\
\text { stimuli and bodily responses (Mindfulness } \\
\text { in Schools Project '.be' programme, } \\
\text { 2013) }\end{array}$ \\
\hline $\begin{array}{l}\text { Session 3: } \\
\text { Introduction } \\
\text { to CBT } \\
\text { model: } \\
\text { Difficult } \\
\text { experiences }\end{array}$ & $\begin{array}{l}\text { - Demo Sensory picture completed by } \\
\text { leader } \\
\text { (e.g. filing nails, people talking while I'm } \\
\text { trying to work) } \\
\text { - Participants consider thoughts, body and } \\
\text { emotion feelings and behaviours while } \\
\text { eating chilli (optional) } \\
\text { - Complete sensory picture for chilli } \\
\text { experience, then for own choice of } \\
\text { difficult sensory experiences }\end{array}$ & - As above \\
\hline $\begin{array}{l}\text { Session 4: } \\
\text { Outcomes of } \\
\text { sensory } \\
\text { experiences: } \\
\text { Helpful or } \\
\text { unhelpful? }\end{array}$ & $\begin{array}{l}\text { - Following demonstration, participants } \\
\text { stick new 'outcome arrows' onto previous } \\
\text { sensory pictures. Considers impact of } \\
\text { their reactions on themselves, and } \\
\text { others at the time and in the future } \\
\text { - Sensory pictures with helpful outcomes } \\
\text { (e.g. having a bath, listening to music) } \\
\text { are introduced as 'coping tools' and } \\
\text { shared with the group, }\end{array}$ & $\begin{array}{l}\text { - } \quad \text { Previous self-reports of unhelpful sensory } \\
\text { coping strategies (Ashburner et al., 2013; } \\
\text { Smith \& Sharp, 2012), suggest outcomes } \\
\text { might not always be considered in autism } \\
\text { - Coping tools' terminology used in } \\
\text { Attwood (2004) } \\
\text { - Highlighting existing coping tools aims to } \\
\text { foster self-efficacy and motivation for } \\
\text { trying out new coping tools }\end{array}$ \\
\hline
\end{tabular}




\begin{tabular}{|c|c|c|}
\hline $\begin{array}{l}\text { Session 5: } \\
\text { Behaviour } \\
\text { coping tools }\end{array}$ & $\begin{array}{l}\text { - Demo: New sensory picture completed } \\
\text { by leader for behaviour coping tools (e.g. } \\
\text { for 'people talking when l'm trying to } \\
\text { work' -- 'ask someone to be quiet' / listen } \\
\text { to music'). } \\
\text { - Role-play inoffensive ways of asking } \\
\text { someone stop doing something. } \\
\text { - Participants decide whether stimuli are } \\
\text { 'controllable' or 'uncontrollable' } \\
\text { - If controllable: think of 'behaviour coping } \\
\text { tools' and make new sensory pictures for } \\
\text { these scenarios }\end{array}$ & $\begin{array}{l}\text { - Demonstrate impact of changing } \\
\text { behaviour on thoughts, feelings and } \\
\text { outcomes - 'psychoeducation' (Hoffman, } \\
\text { 2011) } \\
\text { - Control of stimuli identified as important } \\
\text { Ashburner's (2013) analysis of self- } \\
\text { reports. } \\
\text { Pilot studies and initial interviews } \\
\text { suggested that 'asking others' was an } \\
\text { area of difficulty }\end{array}$ \\
\hline $\begin{array}{l}\text { Session 6: } \\
\text { Body coping } \\
\text { tools }\end{array}$ & 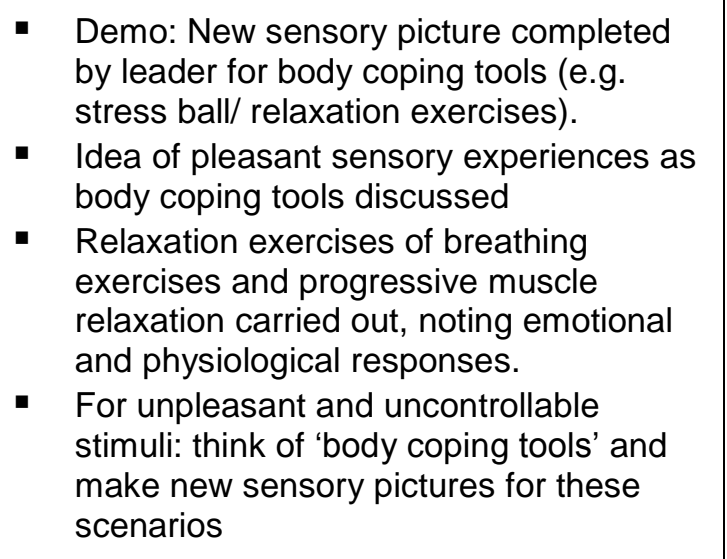 & $\begin{array}{l}\text { - Demonstrate impact of changing feelings } \\
\text { on thoughts, behaviour and outcomes - } \\
\text { 'psychoeducation' (Hoffman, 2011) } \\
\text { - Pleasant sensory experiences used for } \\
\text { calming in Attwood, (2004) and Williams } \\
\text { and Shellenberger (1994). Relaxation } \\
\text { exercises taken from the 'Retracking' } \\
\text { pack (Bates, 1997) } \\
\text { - The autistic author Williams' (1998), } \\
\text { suggests body connectedness', is } \\
\text { necessary for conscious sensory } \\
\text { processing }\end{array}$ \\
\hline $\begin{array}{l}\text { Session 7: } \\
\text { Thinking } \\
\text { coping tools }\end{array}$ & $\begin{array}{l}\text { Demo: New sensory picture } \\
\text { completed by leader for behaviour } \\
\text { for thinking coping tools (e.g. } \\
\text { focussing attention, rationalising and } \\
\text { positive self-talk). } \\
\text { - Visualisation exercise carried out to } \\
\text { demonstrate the effect of focussing } \\
\text { attention } \\
\text { - For unpleasant and uncontrollable } \\
\text { stimuli: think of 'thinking coping tools' } \\
\text { and make new sensory pictures for } \\
\text { these scenarios }\end{array}$ & $\begin{array}{l}\text { Demonstrate impact of changing } \\
\text { thoughts on feelings, behaviour and } \\
\text { outcomes - 'psychoeducation' } \\
\text { (Hoffman, 2011) } \\
\text { - } \quad \text { Thinking coping tools already used } \\
\text { by adolescents with autism } \\
\text { (Ashburner et al., 2013). } \\
\text { Positive-self talk draws on approach } \\
\text { used in the 'Friends' CBT } \\
\text { programme used with typically } \\
\text { developing adolescents (Barrett, } \\
\text { 2004). } \\
\text { Visualisations used for preparation in } \\
\text { the 'Sensory Stories' intervention } \\
\text { (Therapro Inc., 2011). Visualisation } \\
\text { exercises taken from the 'Retracking' } \\
\text { pack (Bates, 1997) } \\
\text { 'Rationalising' or starting a project } \\
\text { suggested to facilitate conscious } \\
\text { sensory interpretation (Ashburner et } \\
\text { al., 2013; Attwood, 2004) }\end{array}$ \\
\hline $\begin{array}{l}\text { Session 8: } \\
\text { Review and } \\
\text { celebration }\end{array}$ & $\begin{array}{l}\text { - The different tools were reviewed } \\
\text { and successful uses shared with the } \\
\text { group } \\
\text { - Participants review their sensory } \\
\text { pictures and make new ones } \\
\text { - As appropriate an unpleasant } \\
\text { sensory experience (e.g. sticky } \\
\text { substance) introduced and } \\
\text { participants apply coping tools. }\end{array}$ & $\begin{array}{l}\text { Reinforce idea of individual } \\
\text { differences/ self in-relation-to others } \\
\text { (Smith \& Sharp, 2012) }\end{array}$ \\
\hline
\end{tabular}


Table 3. Participant measures on outcome variables at pre-intervention, post-intervention and follow-up.

\begin{tabular}{|c|c|c|c|c|c|c|c|c|c|c|}
\hline \multirow{2}{*}{$\begin{array}{c}\text { Measure } \\
\text { (raw } \\
\text { scores) }\end{array}$} & \multirow{2}{*}{ Subscale } & \multicolumn{3}{|c|}{$\begin{array}{l}\text { Pre-intervention } \\
0 \text { weeks }\end{array}$} & \multicolumn{3}{|c|}{$\begin{array}{l}\text { Post-intervention } \\
9 \text { weeks }\end{array}$} & \multicolumn{3}{|c|}{$\begin{array}{l}\text { Follow-up } \\
17 \text { weeks }\end{array}$} \\
\hline & & $M$ & $S D$ & Range & $M$ & $S D$ & Range & $M$ & $S D$ & Range \\
\hline \multirow{5}{*}{ AASPa } & Low registration & 32.00 & 5.72 & $23-39$ & 36.14 & 7.43 & $27-47$ & 36.43 & 5.16 & $28-42$ \\
\hline & Sensation seeking & 39.29 & 5.68 & $33-50$ & 37.71 & 4.75 & $31-44$ & 39.00 & 3.92 & $34-46$ \\
\hline & Sensory sensitivity & 35.71 & 6.05 & $29-45$ & 39.00 & 6.90 & $29-49$ & 40.00 & 4.80 & $34-49$ \\
\hline & Sensation avoiding & 33.86 & 5.96 & $27-40$ & 36.29 & 4.68 & $27-42$ & 37.00 & 4.36 & $29-42$ \\
\hline & Total & 140.86 & 16.59 & $117-163$ & 149.14 & 21.63 & $117-174$ & 152.43 & 12.05 & $129-166$ \\
\hline $\mathrm{SSP}^{\mathrm{b}}$ & Total & 144.17 & 13.99 & $94-189$ & 148.50 & 13.23 & $107-189$ & 148.67 & 16.86 & $103-189$ \\
\hline \multirow{3}{*}{$\mathrm{RBQ}^{\mathrm{c}}$} & $\begin{array}{r}\text { Insistence on } \\
\text { Sameness/ } \\
\text { Circumscribed } \\
\text { Interests }\end{array}$ & 4.14 & 5.81 & $0-16$ & & & & 6.14 & 6.09 & $0-15$ \\
\hline & $\begin{array}{r}\text { Sensory/Motor } \\
\text { Behaviours }\end{array}$ & 7.43 & 5.80 & $1-18$ & & & & 7.43 & 8.62 & $0-23$ \\
\hline & Total & 13.71 & 11.80 & 3-37 & & & & 15.57 & 15.60 & $0-44$ \\
\hline SCAS-P $P^{d}$ & Total & 20.86 & 15.89 & $4-46$ & & & & 27.00 & 15.33 & $9-54$ \\
\hline
\end{tabular}

Notes. ${ }^{\text {aAASP }}=$ Adolescent/Adult Sensory Profile. Scores above and below normative ranges indicate more or fewer sensory sensitivities than normal. Normative ranges: Low registration: 27 - 40, sensation seeking, 42 - 58, sensory sensitivity: 26 - 40, sensation avoiding: 26 - 40, Total: not available (Brown and Dunn, 2002). bSSP $=$ Short Sensory Profile. Lower scores indicate more atypical sensory behaviours. Compared to normative data, (Dunn, 1999), two adolescents scored in the range of 'typical performance', three in the 'probable difference' range and two in the 'definite difference' range; 'c $\mathrm{RBQ}=$ Repetitive Behaviour Questionnaire. Higher scores indicate greater levels of repetitive behaviours. Normative ranges: Insistence on sameness/circumscribed interests: 0 - 2.39, sensory/motor behaviours: 0 - 3.38, total: 0 - 4.78 (Honey et al., 2012). ${ }^{\text {SSCAS}}-\mathrm{P}=$ Spence Children's Anxiety Scale - Parent. Higher scores indicate greater levels of anxiety. Normative range for Total score: 3.5 - 20.1 (Nauta et al., 2004). 